\title{
Organização prosódica e efeitos de sentido em quatro diferentes interpretações de "Na Batucada da Vida"
}

\author{
RENATA PELLOSO GELAMO*
}

\begin{abstract}
RESUMO: Proponho, neste estudo, um olhar sobre o fenômeno da voz, no qual aspectos linguísticos da interpretação vocal de uma canção possam ser levados em conta. Com base na teoria da Fonologia Prosódica, proponho compreender como um grupo de juízes percebe auditivamente, a maneira como Carmen Miranda, Dircinha Batista, Elis Regina e Ná Ozzetti organizam prosodicamente o texto da canção "Na batucada da vida". Analiso mais especificamente a percepção de como as intérpretes organizam e delimitam a frase entonacional (I), constituinte da hierarquia prosódica cujos limites podem ser marcados por pausas. Como I é um constituinte que leva em conta para sua definição elementos semânticos, a criação de diferentes efeitos de sentido em cada interpretação pode ser definida a partir dos diferentes modos de organizar I. Ao compactuar com a visão de que voz $e$ linguagem não se separam, demonstro, com base nos diferentes modos de organizar a frase entonacional, as possíveis atribuições de sentido para as interpretaçoes. Aos diferentes modos de organização, atribuem-se marcas de subjetividade das intérpretes. Por outro lado, as semelhanças podem decorrer da influência das intérpretes mais antigas sobre as mais recentes, assim como da influência de informações de natureza musical.
\end{abstract}

PALAVRAS-CHAVE: Interpretação vocal. Prosódia. Canção popular brasileira. Efeitos de sentido.

\footnotetext{
* Renata Pelloso Gelamo possui graduação em Fonoaudiologia (2001) e mestrado em Estudos Linguísticos (2006) pela Unesp, onde desenvolveu pesquisa sobre a interpretação de canções populares brasileiras (organização prosódica e criação de efeitos de sentidos). Doutoranda em Artes (Arte e Educação) pelo Instituto de Artes da Unesp (desde 2014), com pesquisa sobre diferentes experiências com o canto coletivo. Coordenadora do projeto Ateliê de Voz. E-mail: renatagelamo@gmail.com
} 


\title{
Prosodic organization and meaning effects in four different interpretations of "Na Batucada da Vida"
}

\begin{abstract}
In this study we propose a look on the voice phenomenon, in which linguistic aspects of voice interpretation in a song can be taken into account. Based on the theory of Prosodic Phonology, we aim to understand how a group of judges auditively perceive the way in which Carmen Miranda, Dircinha Batista, Elis Regina and Ná Ozzetti prosodically organize the lyrics of the song "Na Batucada da Vida". More specifically we analyze the perception of how the interpreters organize and delimit the Intonational Phrase (I), a constituent of prosodic hierarchy, whose limits can be marked by pauses. Since I is a constituent that takes into account semantic elements for its definition, the creation of different meaning effects in each interpretation can be defined from the different ways in which the interpreters organize I. Considering the view that voice and language are inseparable, we demonstrate, based on the different ways of organizing the Intonational Phase, the possible attributions of meaning to the interpretations. The ways in which the interpreters organize I are influenced by their subjectivity marks. On the other hand, similarities may be explained by the influence of previous interpreters on more recent ones as well as the influence of information of musical nature.
\end{abstract}

KEYWORDS: Vocal interpretation. Prosody. Brazilian Popular Song. Meaning effects. 


\section{Da fisiologia à linguagem}

$\mathrm{D}$ urante minha graduação em Fonoaudiologia, quando iniciei os estudos acadêmicos sobre a voz cantada, pude observar uma escolha da área por um viés que compreende a voz como o resultado de ajustes motores, principalmente aqueles realizados pelos músculos das pregas vocais e do trato vocal. Nesse modo de compreender a voz não havia espaço para o sujeito produtor da voz, tampouco para os sentidos produzidos por sua voz. A proposta de atuação de um fonoaudiólogo com cantores era, àquela época, portanto, um trabalho focado em terapias de patologias vocais, enfatizando o estudo e a prática da dimensão técnica da voz cantada. A grande preocupação era a de adaptar as vozes dos cantores, buscando, assim, o chamado equilíbrio sonoro por meio de técnicas vocais que permitiam o mínimo de esforço e o máximo de rendimento. Estas práticas visavam proporcionar o que se entende como vozes "saudáveis" e "equilibradas", fazendo pouca ou nenhuma menção a elementos subjacentes à interpretação de uma canção, especialmente os de natureza linguística (tais como os prosódicos e os semânticos), constitutivos da interpretação/atuação do cantor.

Esse modo de compreender a voz nas tendências dominantes na área da Fonoaudiologia mostravam uma grande lacuna no que se refere ao estudo da interpretação vocal, visto que, nesses trabalhos a voz é vista predominantemente em sua dimensão fisiológica desvinculada da linguagem.

No intuito de investigar um modo mais integrado de compreender a voz, aprofundei minha pesquisa sobre o fenômeno da voz cantada durante o curso de mestrado na área da Linguística, sob orientação do linguista Lourenço Chacon, quando então, procurei um olhar para a voz em que pudesse ser compreendida como linguagem e, consequentemente, demonstrar quais eram os possíveis efeitos de sentidos presentes nas interpretações de canções.

Pareceu-me que para um bom desempenho de minha atuação como fonoaudióloga, pesquisadora e profissional que estuda e atua com a linguagem, a busca de subsídios na Linguística, a exemplo de como é feita em outras áreas da Fonoaudiologia, era essencial para que o trabalho com cantores pudesse se dar de 
maneira mais efetiva. Ao meu ver, era importante buscar conhecimentos sobre a interpretação vocal a partir de conhecimentos linguísticos, além de conhecimentos técnicos, a fim de que, como fonoaudióloga, pudesse enriquecer o trabalho com o cantor preocupado com o aprimoramento vocal, numa maior abrangência de sua significação.

Para tanto, propus um estudo linguístico da voz, mais aprofundado e subsidiado pelo componente prosódico da linguagem. A partir de tal estudo, entendi que a voz cantada pode ser vista não mais isoladamente, mas sim dentro de um contexto que abrange a interpretação musical e, junto com ela, efeitos de sentido que a organização prosódica da voz é capaz de criar.

\section{Voz como linguagem - base teórica}

Na Linguística, vários estudos sobre prosódia têm procurado demonstrar seu papel na estruturação da linguagem. Como afirma Cagliari (1993), “os aspectos prosódicos da fala não servem para enfeitar a fala, fazem parte da própria essência da linguagem oral" (p.42).

De um ponto de vista fonológico, tal como aquele proposto por Nespor e Vogel (1986), a organização prosódica da linguagem obedeceria a determinados algoritmos, os quais possibilitariam a criação de constituintes prosódicos na própria língua. Segundo tais autoras, essa organização prosódica é determinada hierarquicamente (e não linearmente, como o pensavam os estudiosos da Fonologia Gerativa Clássica) em constituintes tais como a sílaba, o pé, a palavra fonológica, o grupo clítico, a frase fonológica, a frase entonacional e o enunciado fonológico. Tais constituintes, segundo as autoras, podem ser o domínio de aplicação de regras fonológicas características de uma determinada língua. Além disso, essa organização prosódica obedeceria a regras que lançam mão de informações de outros componentes da gramática (como a morfologia, a sintaxe e a semântica) para a definição de constituintes prosódicos, embora de modo não-isomórfico - já que, para que se possa definir o domínio, é necessário e fundamental algum tipo de pista fonética. 
Em razão dessa maneira de se ver a linguagem oral e pensando que a interpretação de canções deveria levar em conta fatos linguísticos como a organização prosódica do texto, é de grande importância para o cantor atentar para as possibilidades dessa organização nas canções, no que diz respeito à criação de efeitos de sentido pretendidos por sua interpretação. Visando demonstrar essa importância, focalizarei o papel do constituinte frase entonacional $(I)$ em diferentes interpretações de uma mesma canção - conforme especificado mais abaixo. Mas antes, farei uma breve exposição sobre esse constituinte da hierarquia prosódica.

A frase entonacional constitui uma unidade prosódica definida como um conjunto de frases fonológicas ou apenas uma frase fonológica. Bisol (1996) salienta que existem duas características para a identificação de uma frase entonacional: (a) em uma sequência de frases fonológicas que constituam uma I, uma delas é forte por características semânticas, e todas as demais são fracas; (b) uma sentença - em geral, declarativa, exclamativa ou interrogativa - tem sempre um contorno entonacional determinado, "mas no interior destas unidades sempre se tem que contar com certa flexibilidade" (BISOL, 1996, p. 258).

No domínio da frase entonacional, as informações sintático-semânticas são fortemente mobilizadas. São também mobilizados, em sua constituição, "fatores de performance tais como velocidade de fala e estilo, que podem afetar o número de contornos entonacionais contidos num enunciado" (NESPOR e VOGEL, 1986). A regra básica de formulação desse constituinte é a de que I é domínio de um contorno entonacional e de que seu limite final coincide com posições nas quais pausas podem ser introduzidas em uma sentença. O que se percebe como pausa, segundo Nespor e Vogel (1986), não necessariamente corresponde a um silêncio. As "pausas percebidas", como descritas pelas autoras, funcionam como limites de constituintes e podem ser caracterizadas por uma variedade de fenômenos, tais como mudanças de frequência e de duração.

O domínio de I frequentemente corresponde a um constituinte sintático, mas sem isomorfia, já que a organização fonológica muitas vezes difere da organização sintática. Uma das razões dessa não-isomorfia é a de que a organização da frase entonacional (I) pode ser reestruturada, determinada pela sua extensão e 
pela velocidade e estilo de fala (ou do canto) em que ocorre, além, ainda, de sua proeminência relativa (de acordo com determinados critérios e de acordo com algumas restrições). As restrições mais importantes são: (a) evitar reestruturação em qualquer lugar que não corresponda ao final de uma frase nominal; (b) evitar separação entre um argumento obrigatório e seu verbo.

No interior desse quadro, a proposta neste artigo é analisar de que modo quatro grandes nomes da Música Popular Brasileira (Carmen Miranda, Dircinha Batista, Elis Regina e Ná Ozzetti) interpretam a canção “Na Batucada da Vida”, de autoria de Ary Barroso e Luís Peixoto (1934). Para tanto, buscarei compreender de que maneira tais intérpretes organizam prosodicamente o texto de tal canção - mais especificamente, como o organizam as frases entonacionais, tais como definidas pelo algoritmo estabelecido por Nespor e Vogel (1986) - segundo a percepção de um conjunto de juízes.

\section{A canção, as intérpretes e a frase entonacional}

Na Música Popular Brasileira, existem vários gêneros musicais que foram se definindo a partir de mudanças sociais, políticas e culturais ocorridas no decorrer do tempo. Dentre esses gêneros, será destacado, neste estudo, o samba-canção, gênero musical da canção a ser tematizada.

A canção estudada, "Na Batucada da Vida", foi composta por Ary Barroso e Luís Peixoto em 1934. Tal canção foi escolhida para o estudo por ter sido gravada por quatro intérpretes em épocas bem distintas. Foi gravada, pela primeira vez, por Carmen Miranda no mesmo ano de sua composição. Mais tarde, Dircinha Batista, em 1950. Elis Regina regravou esta canção em 1974 e, Ná Ozzetti, em 2001.

Como o objetivo é observar o papel do constituinte frase entonacional nesta canção, foi feita uma comparação entre as quatro diferentes interpretações. Como um dos critérios para a delimitação da frase entonacional é a presença de pausas, elas foram localizadas nessas diferentes interpretações.

As pausas foram delimitadas com base na concordância entre um grupo de nove juízes, formado por três linguistas, três músicos e três fonoaudiólogos, todos 
com informação musical e/ou linguística (no campo da fonologia). Esses juízes demarcaram, no texto da canção, os momentos em que julgavam haver pausa. Consideramos os pontos que obtiveram uma concordância acima de $70 \%$ como critério para a identificação de possíveis limites de frases entonacionais nas diferentes interpretações.

A seguir, apresento como os juízes detectaram os pontos de pausa em cada uma das interpretações. Os constituintes delimitados a partir de pausas que coincidiram com possíveis limites de frase entonacional foram marcados entre colchetes. As estruturas criadas a partir de pausas, mas que não coincidiram com limites de frase entonacional, foram marcadas com barras simples.

$\mathrm{Na}$ interpretação de Carmen Miranda (CM), foi detectado um total de 28 pausas, sendo que $24(85,70 \%)$ coincidiram com pontos em que pausas podem definir limites de $I$ e 4 (14,30\%) localizaram-se em pontos que não coincidem com esses limites.

[No dia / em que apareci no mundo] $I$ [juntou / uma porção de vagabundo da orgia] $I$ [de noite] ${ }_{I}$ [teve choro e batucada] $I$ [que acabou de madrugada] ${ }_{I}$ [em grossa pancadaria] ${ }_{I}$

[Depois / do meu batismo de fumaça] I [mamei um litro e meio de cachaça bem puxado] $I$ [e fui adormecer como um despacho] ${ }_{I}$ [deitadinha no capacho] ${ }_{I}[\text { na porta dos enjeitados }]_{I}$

[Cresci] I [olhando a vida sem malícia $]_{I}$

[quando um cabo de polícia] I [despertou meu coração] I

[Mas como / eu fui pra ele muito boa] I [me soltou na rua à toa] $I$ [desprezada como um cão] I

[Agora] I [que eu sou mesmo da virada] $I$ [e que não tenho nada nada] $I$ [e de Deus fui esquecida] ${ }_{I}$

[Irei cada vez mais me esmolambando] I [seguirei sempre sambando] $I$ 
[na batucada da vida $]^{1}$

Por sua vez, na interpretação de Dircinha Batista (DB), foi detectado um total de 28 pausas, sendo que $23(82,14 \%)$ coincidiram com limites possíveis de $I$ e 5 $(17,86 \%)$ não coincidiram:

[No dia / em que apareci no mundo] ${ }_{I}$ [juntou / uma porção de vagabundo] $I$ [da orgia de noite] $I^{2}$ [teve samba e batucada] $I$ [que acabou de madrugada] ${ }_{I}[\text { em grossa pancadaria }]_{I}$

[Depois / do meu batismo de fumaça] ${ }_{I}$ [mamei um litro e meio de cachaça $]_{I}[$ bem mamados] $I$ [e fui adormecer como um despacho] $I$ [deitadinha no capacho] ${ }_{I}$ [na porta dos enjeitados $]_{I}$

[Cresci olhando o mundo sem malícia] $I$

[quando um cabo de polícia] ${ }_{I}$

[despertou meu coração] $I$

[E como / eu fui pra ele muito boa $]_{I}$ [me soltou no mundo à toa $]_{I}$ [desprezada como um cão] ${ }_{I}$

[Agora que eu sou mesmo da virada] $I$ [e topo qualquer parada] $I$ [por um prato de comida] $I$

[Irei / cada vez mais me esmolambando] $I$ [seguirei sempre sambando] I [na batucada da vida]

Já na interpretação de Elis Regina (ER), foi detectado um total de 27 pausas, sendo que $25(92,60 \%)$ coincidiram com limites de $I$ e $2(7,40 \%)$ não coincidiram:

\footnotetext{
1 Desconsideramos a possível percepção desta pausa, nesta e nas seguintes interpretações, por coincidir com o final do material linguístico do texto.

${ }^{2}$ A estrutura [da orgia de noite], diferentemente do que acontece nas outras interpretações, aparece como um único constituinte devido ao fato de que, na interpretação de Dircinha Batista, o limite entre da orgia e de noite é caracterizado acusticamente por um alongamento com portamento. Como não foi solicitado esse tipo de análise dos juízes, mas sim apenas a assinalação da presença ou da ausência de pausas, considerarei a pausa percebida no final de [da orgia de noite] como limite de frase entonacional.
} 
[No dia em que eu apareci no mundo] ${ }_{I}$ [juntou / uma porção de vagabundo] ${ }_{I}[\text { da orgia }]_{I}$ [de noite] ${ }_{I}$ [teve samba e batucada] ${ }_{I}$

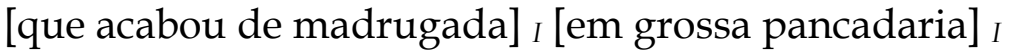

[Depois / do meu batismo de fumaça $]_{I}$ [mamei um litro e meio de cachaça $]_{I}\left[\right.$ bem puxado] ${ }_{I}$ [e fui adormecer como um despacho] ${ }_{I}$ [deitadinha no capacho] ${ }_{I}$ [na porta dos enjeitados] ${ }_{I}$

[Cresci] $]_{I}$ [olhando a vida sem malícia $]_{I}$ [quando um cabo de polícia] I [despertou meu coração] ${ }_{I}$

[E como eu fui pra ele muito boa $]_{I}$ [me soltou na rua $]_{I}[\text { à toa }]_{I}$ [desprezada como um cão] ${ }_{I}$

[E hoje que eu sou mesmo da virada] ${ }_{I}$ [e que não tenho nada nada] ${ }_{I}$ [que por Deus fui esquecida] $I$

[Irei cada vez mais me esmolambando] $I_{I}$ [seguirei sempre cantando] $I$ [na batucada da vida]

Por fim, na interpretação de Ná Ozzetti (NO), foi detectado um total de 30 pausas, sendo que $25(83,33 \%)$ coincidiram com limites de $I$ e $5(16,67 \%)$ não coincidiram:

[No dia / em que apareci no mundo] ${ }_{I}$ [juntou / uma porção de vagabundos da orgia] $I$ [de noite] ${ }_{I}$ [teve choro e batucada] ${ }_{I}$ [que acabou de madrugada $]_{I}[\text { em grossa pancadaria }]_{I}$

[Depois / do meu batismo de fumaça $]_{I}$ [mamei um litro e meio de cachaça $]_{I}[\text { bem puxado }]_{I}$ [e fui adormecer como um despacho] $I$ [deitadinha no capacho] ${ }_{I}$ [na porta dos enjeitados] ${ }_{I}$

[Cresci] ${ }_{I}$ [olhando a vida sem malícia $]_{I}$ [quando um cabo de polícia] ${ }_{I}$ 
[despertou meu coração] $I_{I}$

[E como / eu fui pra ele muito boa $]_{I}$

[me soltou na rua à toa] $I$

[desprezada como um cão] $I$

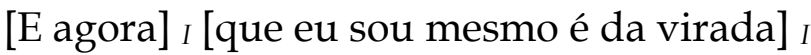

[e que eu não tenho nada nada] $I$

[que por Deus fui esquecida] I

[Irei / cada vez mais me esmolambando] $I$

[seguirei sempre cantando] $I$

[na batucada da vida]

\section{Frase entonacional e efeitos de sentido}

Levando-se em conta a definição de frase entonacional apresentada anteriormente, a seguir analiso como se comportam os dados em relação a esse constituinte prosódico.

O elevado percentual de pausas que coincidem com limites possíveis de Is (em todas as interpretações o índice foi superior a 82\%) e, portanto, que obedecem ao algoritmo, sugere que as intérpretes se orientam, em grande medida, por fatos linguísticos que definem esse constituinte prosódico.

A localização das pausas, tal como percebida pelos juízes, variou em cada interpretação. Com efeito, verifiquei, a partir dos diferentes locais de detecção de pausas, diferentes modos de organização prosódica da formulação linguística de uma mesma canção. Como resultado dessa diferença, observa-se a definição de constituintes com variadas extensões entre as intérpretes.

A variabilidade dos limites de $I$, no que se refere à sua extensão, explica-se pela regra de reestruturação prevista pela formulação deste domínio por Nespor \& Vogel (1986), o que possibilita diferentes arranjos prosódicos. É o que as diferentes organizações de mesmos trechos da canção, tais como percebidas em cada uma das intérpretes, parecem sugerir:

1.a) [Uma porção de vagabundo da orgia] (CM e NO) [Uma porção de vagabundo] [da orgia] (DB e ER) 
1.b) [Mamei um litro e meio de cachaça bem puxado] (CM) [Mamei um litro de meio de cachaça] [bem puxado] (DB, ER e NO)

1.c) [Cresci] [olhando a vida sem malícia] (CM, ER e NO) [Cresci olhando o mundo sem malícia] (DB)

1.d) [Agora] [que eu sou mesmo da virada] (CM e NO) [Agora que eu sou mesmo da virada] (DB) [E hoje que eu sou mesmo da virada] (ER)

Inversamente, estruturas criadas a partir da não-obediência ao algoritmo sugerem que as intérpretes se orientam por outro tipo de informação da canção, uma vez que rompem com as "regras linguísticas" determinadas pelo algoritmo para a construção da frase entonacional. Como vimos, embora o algoritmo para a construção da frase entonacional suponha grande variabilidade para os limites e para a extensão da frase entonacional, essa variabilidade deve obedecer a certas restrições. Uma das restrições mais importantes é a de se evitar reestruturação em qualquer lugar que não corresponda ao final de um sintagma nominal (SN). Tal tendência não é verificada, por exemplo, nos casos a seguir:

2.a) [No dia / em que apareci no mundo] (CM, DB e NO)

2.b) [Depois / do meu batismo de fumaça] (CM, DB, ER e NO) ${ }^{3}$

Outra tendência geral é a de se evitar separação entre um argumento obrigatório e seu verbo, até mesmo se tal divisão respeita a restrição citada anteriormente, de SN. Mas, nas quatro intérpretes, pelo menos uma vez essa tendência não foi verificada:

3.a) [Juntou / uma porção de vagabundos da orgia] (CM, DB, ER e NO)

Conforme se vê, ocorreu, no ponto percebido como de pausa, uma ruptura entre o verbo e o argumento que funciona como seu sujeito posposto, ruptura normalmente não verificada (prosodicamente) em enunciados falados sem hesitação.

\footnotetext{
${ }^{3}$ Como se pode observar, os pontos de pausa encontram-se no interior do $\mathrm{SN}$.
} 
Já nos trechos seguintes, observam-se estruturas não condizentes com a organização da frase entonacional, na medida em que, em (4a) verifica-se uma separação entre um conectivo e a oração subordinada que ele introduz e, em (4b), uma junção ("cada vez mais me esmolambando") entre um elemento deslocável ("cada vez mais") e o verbo principal ("me esmolambando") de uma locução verbal ("irei me esmolambando"):

4.a) [E como / eu fui pra ele muito boa] (CM, DB e NO)

4.b) [Irei / cada vez mais me esmolambando] (DN e NO)

Outro exemplo de não obediência ao algoritmo proposto para a frase entonacional pode ser observado no seguinte trecho:

5.a) [Da orgia de noite] [teve samba e batucada] (DB)

Como se pode notar, a pausa não é observada, conforme a percepção dos juízes, entre a estrutura da orgia e a estrutura de noite, na interpretação de Dircinha Batista. Em todas as outras interpretações ocorreu pausa neste local. Ressalte-se, porém, que Dircinha Batista se utiliza de outro recurso (um alongamento com portamento ${ }^{4}$ ) para delimitar o constituinte frase entonacional, conforme se pode observar neste trecho circulado da partitura:

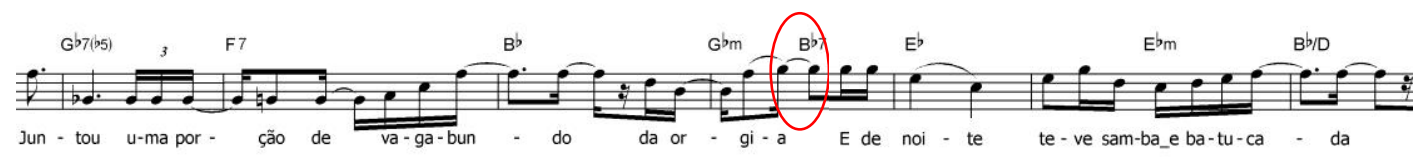

Figura 1. $O$ trecho circulado da partitura mostra o alongamento realizado por Dircinha Batista. Observe-se que as duas notas destacadas têm a mesma altura melódica e estão unidas por uma ligadura, fato que demonstra a existência de um alongamento neste momento.

O trabalho das intérpretes, tal como percebido pelos juízes, pode ter sido influenciado por informações de natureza musical nesses casos de ruptura com

\footnotetext{
${ }^{4}$ Apesar de não ser transcrito, nesse trecho da partitura, um portamento, percebe-se auditivamente sua realização. O portamento caracteriza-se pelo efeito de ligação entre duas notas musicais que compõem um intervalo melódico passando-se, com rapidez, pelos sons intermediários a essas duas notas.
} 
preceitos sintáticos embutidos na constituição da frase entonacional. Veja-se, a propósito, trecho de resposta da cantora Ná Ozzetti a pergunta feita5:

P: Que tipo de preocupação você tem com relação ao texto de uma canção? Você faz um estudo separado, do texto, antes de decidir como irá interpretálo na canção?

R: A letra é fundamental, acabo escolhendo uma canção na maior parte das vezes pela qualidade desta, mas não consigo tratá-la separadamente da música. (destaque nosso).

Não por acaso, nestes dados, em sua totalidade, as estruturas criadas a partir da não-obediência à regra de construção da frase entonacional parecem destacar a organização rítmica característica do gênero samba, na qual relações entre pausas e síncopas ${ }^{6}$ são bastante frequentes. Nesses momentos de destaque, as pausas que não coincidiram com limites de frase entonacional reforçam a combinação entre uma mesma estrutura rítmica e a repetição de um mesmo desenho melódico, correspondentes a "no dia", "juntou" e "depois" - em "mas como", mantém-se a estrutura rítmica, mas com uma leve alteração melódica. Observem-se os momentos de destaque circulados nos respectivos trechos da partitura de Carmen Miranda:

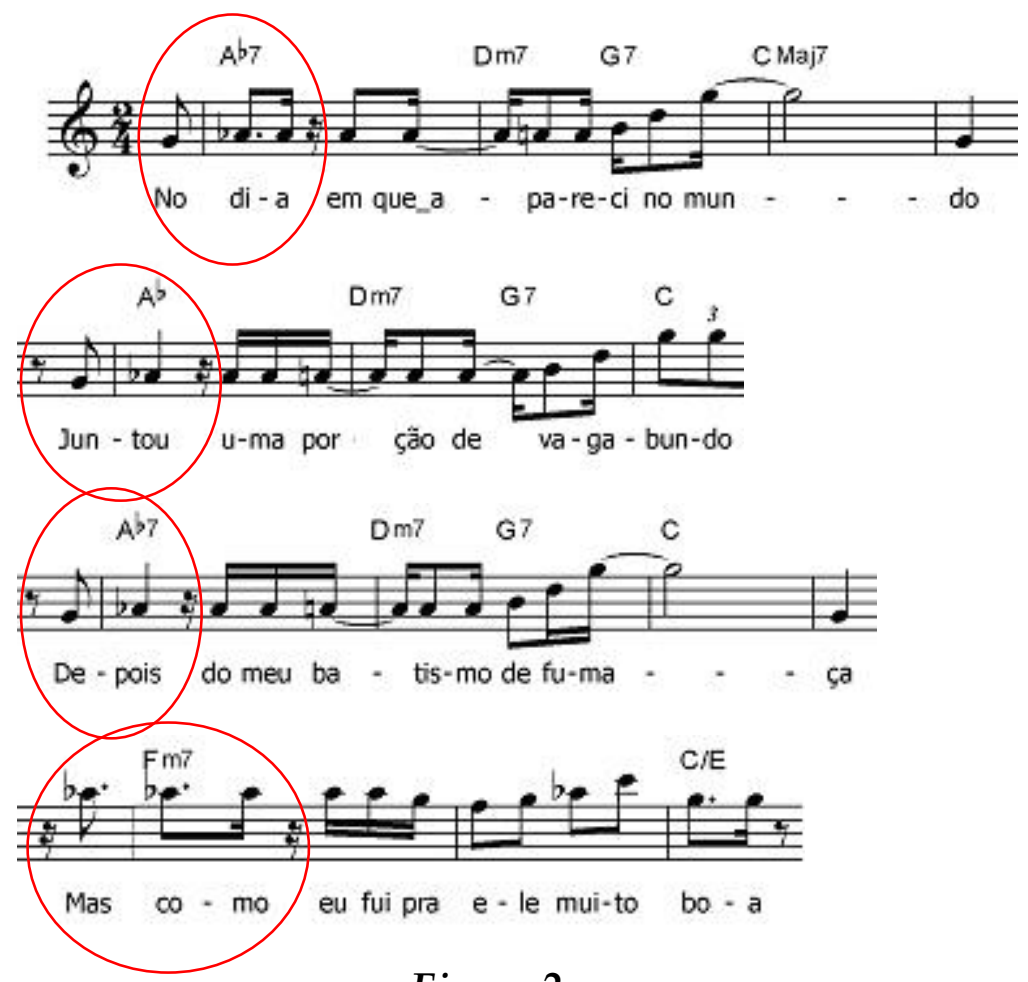

Figura 2.

\footnotetext{
${ }^{5}$ Essa e outras questões foram dirigidas à cantora Ná Ozzetti em entrevista realizada por e-mail. Confira conteúdo completo em Gelamo (2006).

${ }^{6}$ Trata-se do apoio (com acento e maior duração) na nota correspondente a um tempo fraco ou a uma parte fraca do tempo musical da melodia.
} 
Igualmente, na interpretação de Dircinha Batista, observa-se que as pausas não coincidentes com limites de frase entonacional, assim como percebidas pelos juízes, ressaltam a conjunção entre uma mesma estrutura rítmica e um mesmo desenho melódico, correspondente à estrutura "no dia". Nos trechos circulados, correspondentes a "depois" "juntou", “e como" e "irei”, observa-se a mesma estrutura rítmica, mas com variação melódica:

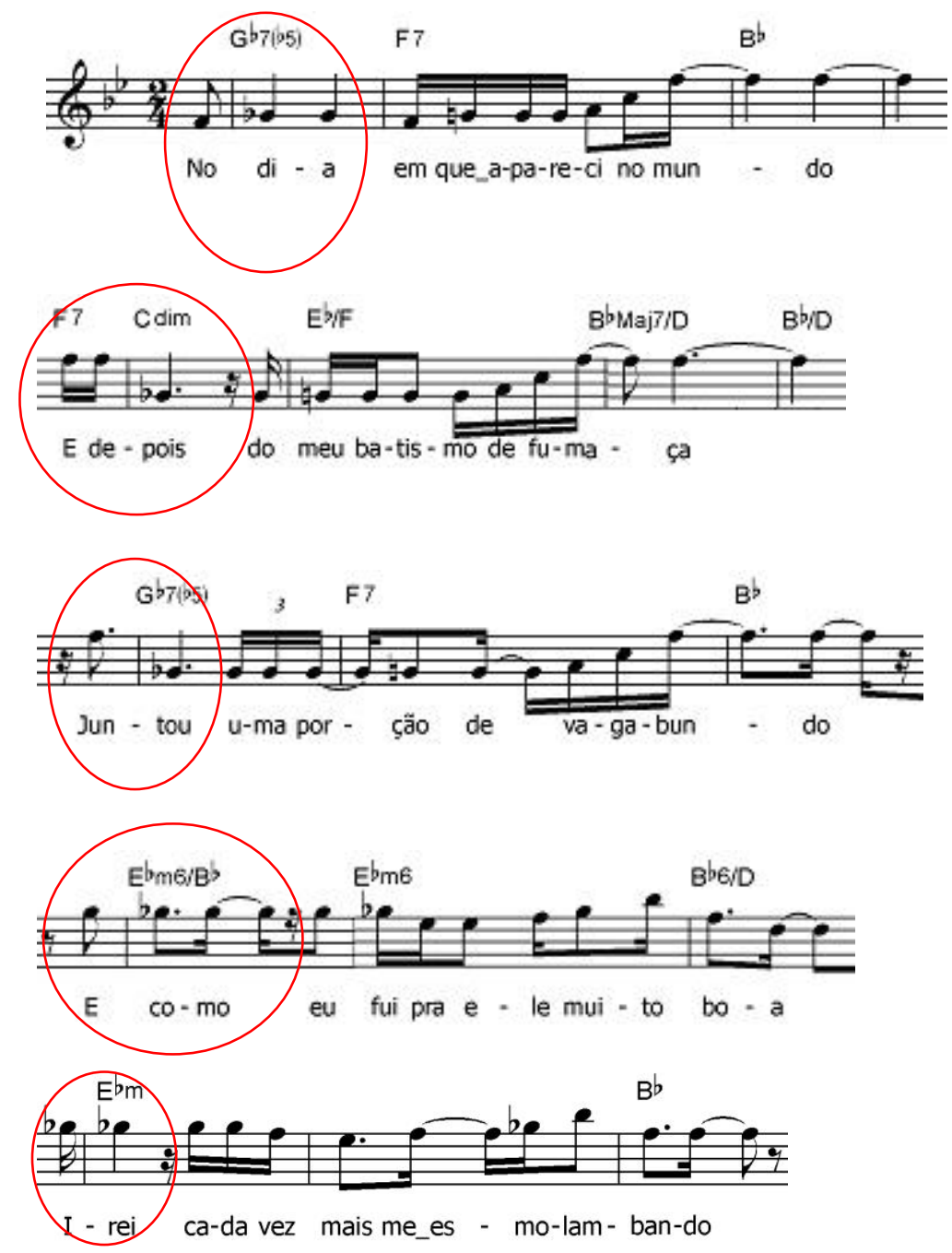

Figura 3.

Já na interpretação de Elis Regina, houve diferenças no que se refere a destaques a essa mesma estrutura rítmica. Nos trechos abaixo, a estrutura rítmica correspondente a "no dia" e "e como" não foi ressaltada pela presença de pausa, nessa interpretação. Mas, semelhantemente a Carmen Miranda e a Dircinha Batista, a 
conjunção entre estrutura rítmica e desenho melódico foi ressaltada em "depois" e “juntou”. É o que mostram os trechos circulados a seguir:
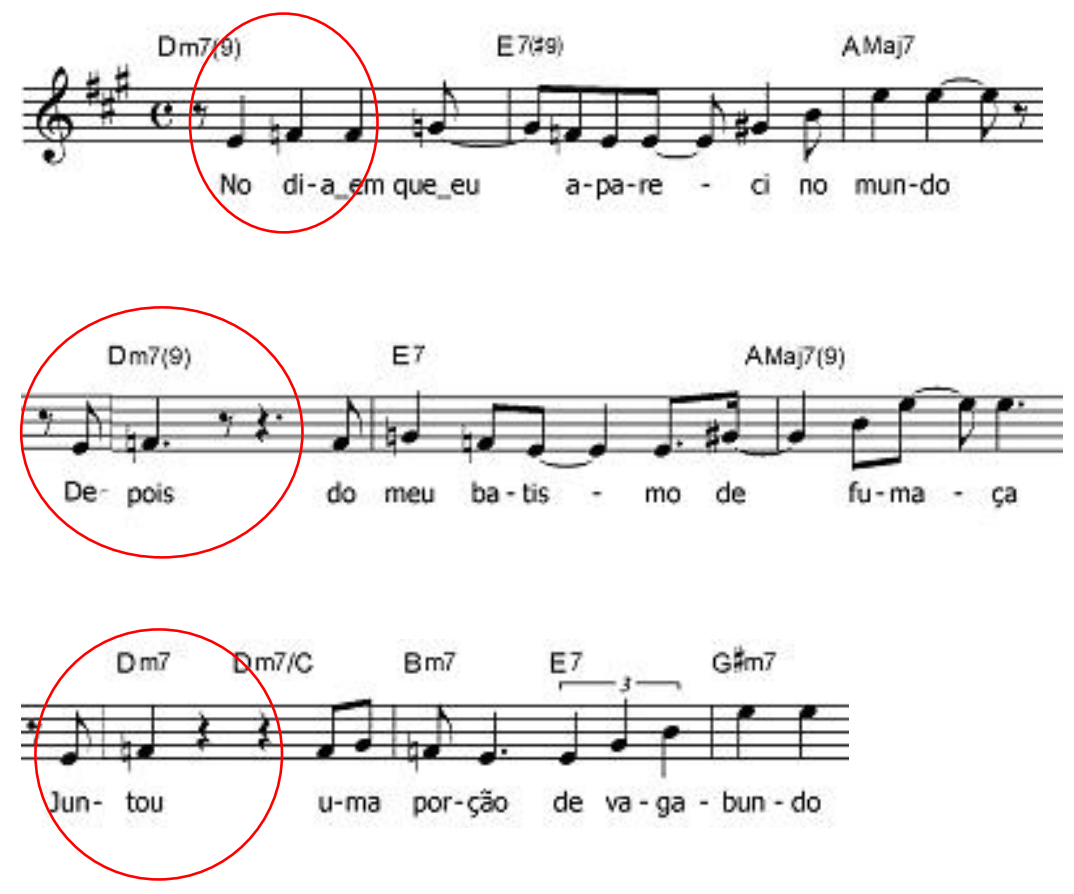

Figura 4.

Finalmente, na interpretação de Ná Ozzetti, assim como acontece nas interpretações de Carmen Miranda e Dircinha Bastista, as pausas percebidas que não coincidiram com possíveis limites de frase entonacional também ressaltam a conjunção entre estrutura rítmica e desenho melódico (com algumas pequenas variações). É o que se pode verificar nas estruturas circuladas "no dia", "depois", "juntou", "e como" e "irei": 


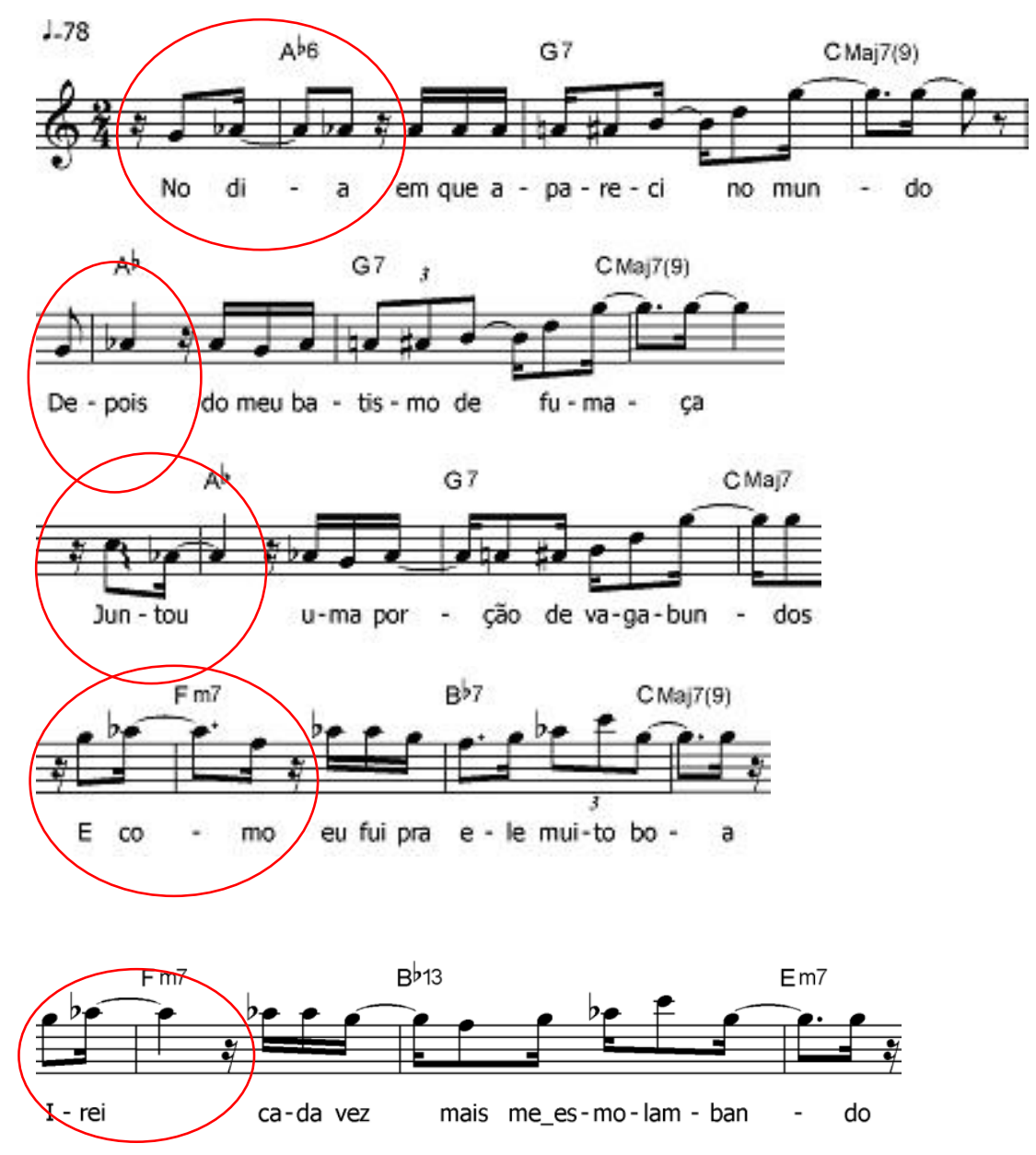

Figura 5.

Mas, independentemente dessa não-adequação ao algoritmo, a variabilidade dos limites também fornece pistas de que os diferentes modos de organização do constituinte frase entonacional, tal como percebido por nossos juízes, podem produzir diferentes efeitos de sentido para as interpretações. Observem-se as diferentes organizações dos trechos da canção e as possíveis diferenças de atribuição de sentido a partir de sua estrutura prosódica:

(6a) [No dia / em que apareci no mundo $]_{I}(\mathrm{CM}, \mathrm{DB}$ e NO)

(6b) [No dia em que apareci no mundo $]_{I}(\mathrm{ER})$

Na ocorrência (6a), a percepção de pausa após a estrutura "no dia" em CM, DB e NO resulta em rompimento da estrutura linguística prevista pela formulação da frase entonacional. Porém, esse rompimento acaba por focalizar o tempo em que se 
desenvolve a ação "aparecer no mundo". Diferentemente, na interpretação de ER (6b), a ausência de pausa não chama a atenção para essa marcação temporal.

(7a) [Uma porção de vagabundo da orgia $]_{I}(\mathrm{CM}$ e NO)

(7b) [Uma porção de vagabundo $]_{I}[\text { da orgia }]_{I}(\mathrm{DB}$ e EL)

Nessa ocorrência, o modo como os juízes percebem a organização que CM e NO (7a) fazem desse trecho da canção aponta para uma única frase entonacional e, portanto, para uma única proeminência. Por outro lado, com base na percepção de pausa pelos juízes, DB e ER organizam este trecho com duas frases entonacionais, das quais a segunda $(7 \mathrm{~b})$ coloca em foco a proveniência ("da orgia”) das personagens englobadas pela expressão "uma porção de vagabundo", que corresponde à primeira frase entonacional.

(8a) [Mamei um litro e meio de cachaça bem puxado $]_{I}(\mathrm{CM})$

(8b) [Mamei um litro de meio de cachaça $]_{I}[\text { bem puxado] }]_{I}(\mathrm{DB}, \mathrm{ER}$ e $\mathrm{NO})$

Nessa ocorrência, os juízes percebem a organização da interpretação de CM (8a) como resultando em uma única frase entonacional e, nas demais intérpretes (8b), como resultando em duas. Consequentemente, em CM, detectam uma única proeminência e, nas outras três intérpretes, duas. Como I é um constituinte no qual a informação semântica interage com a fonológica, o destaque a bem puxado coloca em foco a quantidade com que foi "mamada" a "cachaça". A estrutura bem puxado tornase, pois, na segunda ocorrência, a informação mais importante da oração (vista aqui em termos sintáticos) ou do enunciado fonológico - constituinte prosódico que engloba uma ou mais frases entonacionais.

(9a) $[\text { Cresci }]_{I}$ [olhando a vida sem malícia $]_{I}(\mathrm{CM}, \mathrm{ER}$ e NO)

(9b) [Cresci olhando o mundo sem malícia $]_{I}(\mathrm{DB})$

Nessa ocorrência, os juízes perceberam em CM, ER e NO (9a) duas frases entonacionais. Essa organização focaliza, uma vez mais, o modo como a personagem 
do texto cresceu. Por sua vez, na interpretação que DB faz, pela ausência desse foco (ou, em termos prosódicos, dessa segunda frase entonacional), a estrutura prosódica resultante sugere que a personagem crescia e, concomitantemente, olhava a vida sem malícia.

(10a) $[\text { Agora }]_{I}$ [que eu sou mesmo da virada $]_{I}(\mathrm{CM}$ e NO)

(10b) [Agora que eu sou mesmo da virada] $]_{I}(\mathrm{DB})$

(10c) [E hoje que eu sou mesmo da virada $]_{I}(\mathrm{ER})$

Na ocorrência (10a), observa-se que, em CM e NO, ocorrem duas frases entonacionais e, portanto, duas proeminências. Nessa realização, assim como na ocorrência (6a), é dado foco ao tempo em que se desenvolve a ação, criando-se, assim, um contraste entre dois momentos temporais da estrutura narrativa da canção: o tempo do nascimento, "no dia", tal como focalizado por essas intérpretes em (6a), e o tempo atual da vida da personagem, "agora", focalizado em (10a). Nas outras duas interpretações, (10b) e (10c), o foco temporal não é marcado prosodicamente, uma vez que não acontece a percepção de pausas e, portanto, uma única frase entonacional é constituída.

(11a) [Irei cada vez mais me esmolambando] I $_{\text {(CM e ER) }}$

(11b) [Irei / cada vez mais me esmolambando $]_{I}(\mathrm{DB}$ e NO)

Nessa última ocorrência, observa-se, em CM e em ER (11a), a percepção da constituição de uma única frase entonacional enquanto que, em DB e NO (11b), observa-se a criação de uma estrutura que não obedece aos preceitos que definem uma frase entonacional. Mesmo assim, a presença da pausa, em (11b), pode projetar, na estrutura "cada vez mais me esmolambando", o efeito de modo como se desenvolve essa ação.

As ocorrências (6a), (9a), (10a) e (11b), ao mesmo tempo, ressaltam uma conjunção rítmico-melódica e criam um foco. Uma única exceção parece ocorrer em:

(12a) $[\mathrm{E} \text { como / eu fui pra ele muito boa }]_{I}(\mathrm{CM}, \mathrm{DB}$ e NO)

(12b) [E como eu fui pra ele muito boa ${ }_{I}(\mathrm{ER})$ 
Em (12a), a pausa percebida realça sobretudo um motivo rítmico, uma vez que a estrutura linguística resultante ("e como") não parece, por si só, constituir um foco textual.

Observa-se, nos casos acima, várias semelhanças entre as cantoras. Essas semelhanças remetem à possibilidade de as intérpretes, a partir de Dircinha Batista, terem se baseado nas intérpretes anteriores para a definição de sua interpretação. Destaque-se, a propósito, que a versão de Ná Ozzetti é a que mais se aproxima da primeira versão (a de Carmen Miranda), no que se refere, aqui especificamente, à organização da frase entonacional.

Essas semelhanças remetem a Bakhtin (1992), para quem “(..) nossa fala, isto é, nossos enunciados (...) estão repletos de palavras dos outros" (p. 314). Bakthin (1992) afirma ainda que "o enunciado está repleto dos ecos e lembranças de outros enunciados, aos quais está vinculado no interior de uma esfera comum da comunicação verbal". (p. 316). Ao responder a uma questão dirigida a ela, Ná Ozzetti confirma, a presença desses "ecos" em sua interpretação da canção em estudo. Com efeito, à questão "Você se baseou em alguma das versões de "Na Batucada da Vida" para construir sua interpretação?", a referida cantora responde:

declaradamente na [interpretação] da Carmen Miranda, que eu tinha acabado de descobrir. A da Elis era para mim um clássico, como se a canção tivesse nascido daquela forma e não pudesse ser mudada. A da Carmen me revelou uma outra canção e um outro tempo desta canção. Achei importante fazer esta menção ao que antecedeu uma referência que eu tinha. (OZZETTI, 2005).

Como se pode observar, tanto pela aproximação, quanto pelo distanciamento, a interpretação de Ná Ozzetti, dialoga, respectivamente, com as interpretações de Carmen Miranda e de Elis Regina.

Na interpretação de Elis Regina, porém, observa-se, mais especificamente no que diz respeito à organização da frase entonacional, a relevante presença de características mais individuais de interpretação. Diferentemente do que fazem Carmen Miranda, Dircinha Batista e Ná Ozzetti, essa intérprete modifica o andamento, assim como harmonia e melodia, em sua interpretação. Essas modificações acabam levando a uma organização das frases entonacionais que, 
muitas vezes, distancia-se daquela que fazem as outras três intérpretes. É o que se pode observar nas seguintes ocorrências:

(13a) [No dia em que apareci no mundo] $]_{I}(\mathrm{ER})$

(13b) [No dia / em que apareci no mundo] $]_{I}(\mathrm{CM}, \mathrm{DB}$ e NO)

(14a) [E como eu fui pra ele muito boa $]_{I}(\mathrm{ER})$

(14b) [E como / eu fui pra ele muito boa $]_{I}(\mathrm{CM}, \mathrm{DB}$ e NO)

(15a) [Me soltou na rua $]_{I}$ [à toa $]_{I}(\mathrm{ER})$

(15b) [Me soltou na rua à toa $]_{I}(\mathrm{CM}, \mathrm{DB}$ e NO)

Ao analisar essas três diferentes ocorrências de Elis Regina (13a, 14a e 15a) em relação às outras interpretações, assim como percebidas pelos juízes, observa-se concordâncias e discordâncias com respeito ao que postulam Nespor \& Vogel (1986). Segundo as autoras, é mais provável que um enunciado seja quebrado em partes menores quanto mais lentamente ele for pronunciado. Diferentemente do que postulam Nespor \& Vogel, a velocidade não funciona como critério que determina a reestruturação, pelo menos nas duas primeiras ocorrências (13a e 14a). Com efeito, o andamento mais rápido da interpretação (em Carmen Miranda, em Dircinha Batista e em Ná Ozzetti) resultou em duas estruturas (13a e 14a), ao passo que o andamento mais lento (em Elis Regina) resultou em um único constituinte nessas duas primeiras ocorrências (13a e 14a). Inversamente, porém, na última ocorrência (15a), se pode observar a eficácia do que postulam Nespor \& Vogel, já que foram criadas duas frases entonacionais a partir da enunciação do material linguístico feita com andamento mais lento.

A interpretação de Elis Regina, portanto, remete-nos à possibilidade de atestarmos, também por meio da organização do material linguístico do texto, a presença de marcas de subjetividade entre as intérpretes - questão sugerida por Nespor \& Vogel, na medida em que essas autoras relacionam diferentes possibilidades de reestruturação a questões de estilo individual.

Ressalto, porém, que, mesmo nesse caso, parece haver uma influência não só de um estilo individual, mas também de um estilo de época, assim como de características musicais, intrínsecas ao arranjo, para definição da frase entonacional. 
Neste caso específico da interpretação de Elis Regina ao mudar harmonia, melodia e ritmo, a intérprete (em conjunto com o arranjador) centra-se em características musicais mais difundidas no Brasil após o advento da Bossa Nova, movimento ainda muito influente na canção popular brasileira na época em que a canção foi regravada por Elis. Assim, ao se filiar à Bossa Nova, Elis Regina se distancia de características da canção tradicional brasileira mais presentes na interpretação do gênero samba, tais como marcadas nas versões das outras três intérpretes.

No movimento Bossa Nova, vê-se uma preocupação maior com as chamadas "frases musicais"7 do que com aspectos rítmicos - como acontece no samba tal como interpretado antes (e mesmo depois, como o exemplifica Ná Ozzetti) desse movimento. Essa maior preocupação pode, então, ter "ecoado" na organização das frases entonacionais de Elis Regina, já que, por exemplo, em / No dia em que apareci no mundo/ e em /E como eu fui pra ele muito boa/, elas coincidem com frases musicais.

Como Carmen Miranda, Dircinha Batista e Ná Ozzetti interpretam “Na Batucada da Vida" como samba (ou samba-choro, no caso da última intérprete), aspectos rítmicos subjacentes a este gênero parecem ter sido privilegiados, em detrimento de frases musicais. O samba é caracterizado por "melodias e acompanhamentos altamente sincopados" (GROVE, 1980, p. 447) ${ }^{8}$, ou seja, caracterizado por deslocamentos para um tempo fraco ou para a parte fraca de um tempo musical. Esses deslocamentos, no samba, são muitas vezes marcados por uma pausa: a pausa da síncopa. Esta definição de samba possibilita levantarmos hipóteses que explicam a existência de pausas em locais que rompem a estrutura da frase entonacional, como nas ocorrências citadas nas páginas anteriores.

Mas, se nesses casos de distanciamento entre as intérpretes, fatos de natureza musical parecem ter influenciado o que os juízes perceberam da interpretação de Elis Regina, no que se refere à delimitação da frase entonacional, nos casos de aproximação entre as intérpretes, esses fatos também parecem estar presentes.

\footnotetext{
7 "O termo frase significa, do ponto de vista da estrutura, uma unidade aproximada àquilo que se pode cantar em um só fôlego" (SCHOENBERG, 1996).

8 "[...] samba melodies and accompaniments are highly syncopated [...]" (GROVE, 1980, p. 447.
} 
A fim de levantar algumas hipóteses a respeito da relação entre informações musicais e delimitação de frases entonacionais, entendo que será necessário um estudo ainda mais aprofundado para uma melhor compreensão do fenômeno em canções.

\section{Considerações finais}

Ao propor um olhar diferente para o fenômeno da voz, aqui mais especificamente sobre a voz cantada, busquei subsídios da Linguística por achar que, ao vincular voz e linguagem, poderia contribuir para um enriquecimento do trabalho fonoaudiológico com cantores. Dessa forma, a voz não seria enfocada apenas sob um ponto de vista técnico, mas sim, dentro de um contexto que abrangeria a interpretação musical e, junto com ela, efeitos de sentido que a organização prosódica da voz é capaz de criar.

Como foi possível observar na exposição dos dados, o algoritmo que define o constituinte frase entonacional proposto por Nespor \& Vogel mostrou-se eficaz, uma vez que o número de pausas detectadas que coincidiram com limites desse constituinte foi superior a $82 \%$. Na medida em que a organização prosódica, segundo esse modelo, estaria inscrita na própria competência linguística, e na medida em que observamos um elevado número de pausas que coincidiram com aquelas previstas para a constituição da frase entonacional, conclui-se que a interpretação de canções, mais especificamente sua organização prosódica, pode ser considerada como desempenho linguístico (assim como a fala e a escrita podem ser também assim consideradas). Diante dessa possibilidade de olhar a interpretação de canções, calcada em possibilidades definidas pela própria estrutura da língua (ou da competência linguística), reforça-se ainda mais a necessidade de não se desvincular voz e linguagem na pesquisa e na atuação com o canto.

Ao compactuar com essa visão, de que voz e linguagem não se separam, busquei demonstrar, com base nos diferentes modos de organizar a frase entonacional nas diferentes intérpretes, a possibilidade de diferentes atribuições de sentido para as interpretações. Essa possibilidade de atribuição de sentidos também 
está de algum modo prevista pela formulação do algoritmo desse constituinte. Segundo Nespor \&Vogel (1986), fatores semânticos também podem afetar a organização da frase entonacional. Desse modo, mais uma vez, se pode reforçar a eficácia do algoritmo para a organização da frase entonacional nessas quatro diferentes interpretações da canção "Na batucada da vida".

Mas, como explicar tanto as possíveis semelhanças quanto as possíveis diferenças na organização da frase entonacional tal como percebida na interpretação das quatro cantoras?

Os dados sugerem que as intérpretes se orientam, em grande medida, por fatos de natureza linguística ao fazerem a organização prosódica das canções, no que se refere mais especificamente à frase entonacional. Mas, nessa orientação, as intérpretes parecem explorar diferentes possibilidades desse constituinte. Com efeito, por um lado, diferentes organizações prosódicas criadas a partir de uma mesma disposição sequencial linguística parecem mobilizar diferentes efeitos de sentido para essa sequência; por outro lado, essas diferentes organizações podem ser vistas como marcas de subjetividade das intérpretes - questão também sugerida por Nespor \& Vogel, na medida em que relacionam diferentes possibilidades de reestruturação a questões de estilo individual.

Ainda com relação às semelhanças encontradas na organização da frase entonacional, outros dois fatores poderiam estar na base dessas semelhanças.

Um primeiro fator que destacado na análise é o de, provavelmente, as intérpretes mais recentes terem se baseado nas intérpretes mais antigas para construir sua interpretação. Assim, poderiam (também) ser explicadas as semelhanças entre elas quanto à forma de delimitar a frase entonacional. Essa influência foi textualmente enunciada por Ná Ozzetti, intérprete que mais se aproxima de Carmen Miranda.

Informações de natureza musical podem ter sido outro possível fator de influência nas semelhanças quanto à delimitação da frase entonacional. A maioria dos locais que corresponde musicalmente a finais de frases musicais coincidiu com a maioria dos limites de frase entonacional, tal como feitos pelas intérpretes segundo a percepção dos juízes. Ao que parece, as intérpretes basearam-se também em padrões 
da estrutura rítmico-melódica da canção para a delimitação da frase entonacional, fato que pode explicar muitas semelhanças entre elas.

Com base nesses achados, constata-se que tanto as informações de natureza linguística quanto as informações de natureza musical estão presentes na delimitação da frase entonacional. Conforme observou-se, na medida em que as fronteiras musicais coincidem com limites de frases entonacionais, vê-se que a organização percebida desse constituinte prosódico na interpretação de canções pode ser orientada, também, por aspectos musicais e não apenas linguísticos - fato que aponta para a integração entre esses dois aspectos na estruturação de interpretação de canções.

Por fim, embora a organização prosódica da frase entonacional tenha se mostrado eficaz para a explicação de fatos relativos à interpretação de canções, mas uma vez que a intepretação (como bem o mostrou Ná Ozzetti) vai muito além do que a organização da frase entonacional pode explicar, muitos estudos sobre outras características prosódicas da interpretação devem, ainda, ser feitos para que se possa entender mais claramente o papel da prosódia na interpretação musical no canto. Assim, este estudo deve ser entendido como uma tentativa de apontar para apenas um fato (dentre muitos outros, prosódicos ou não) que explicaria a interpretação de canções.

\section{Referências}

ABERCROMBIE, D. Elements of general phonetics. Edinburgh: Edinburgh Universitty Press, 1967.

BAKTHIN, M. Estética da criação verbal. São Paulo: Martins Fontes, 1992.

BARROSO, A. e PEIXOTO, L. Na Batucada da Vida. Intérprete: Carmen Miranda. In: CARMEN MIRANDA. A pequena notável. Curitiba: Revivendo, p199X. CD. Faixa 14.

Na Batucada da Vida. Intérprete: Dircinha Batista. In: ARY BARROSO. Nossa homenagem 100 anos. Curitiba: Revivendo. CD. Faixa 20.

Na Batucada da Vida. Intérprete: Elis Regina. In: ELIS REGINA. Elis. São

Paulo: PolyGram, p1988. CD. Faixa 2. 
Na Batucada da Vida. Intérprete: Miúcha. In: MIÚCHA \& ANTÔNIO

CARLOS JOBIM. Miúcha/Tom Jobim. RCAVictor, p1977. LP. Faixa 4.

Na Batucada da Vida. Intérprete: Eliseth Cardoso. In: ELISETH CARDOSO. Ary Amoroso. São Paulo: Columbia, p1991. CD. Faixa 2.

Na Batucada da Vida. Intérprete: Ná Ozzetti. In: NÁ OZZETTI. Show. Barueri: Som Livre, p2001. CD. Faixa 8.

BATISTA, C. G. Concordância e fidedignidade na observação. Psicologia, v. 3, n.2, 3949, jul, 1977.

BISOL, L. Constituintes Prosódicos. In. Introdução a estudos de fonologia do português brasileiro. Porto Alegre: EDIPUCRS, 1996, p. 247-61.

CAGLIARI, L. C. Da importância da prosódia na descrição de fatos gramaticais. In. ILARI, R. (org.) Gramática do Português Falado. Campinas: Unicamp/São Paulo: Fapesp, Vol.2: Níveis de Linguística, 1993.

FERREIRA, L. P. Usos da voz em contexto profissional: para além da clínica terapêutica. In: FERREIRA, L. P., ANDRADA, M. A. Saúde Vocal: Práticas Fonoaudiológicas. São Paulo: Roca, 2002.

GELAMO, R. P. Organização prosódica e interpretação de canções: a frase entonacional em quatro diferentes interpretações de $\mathrm{Na}$ Batucada da Vida. Dissertação (Mestrado em Estudos Linguísticos) - Universidade Estadual Paulista, São José do Rio Preto, 2006.

. Expressividade - trajetória da fonoaudiologia brasileira. In: KYRILLOS, L. (org.) Expressividade - da teoria à prática. Rio de Janeiro: Revinter, 2005.

GROVE, G. The new Grove dictionary of music and musicians, edited by Stanley Sadie, 1980.

NESPOR, M.; VOGEL, I. Prosodic Phonology. Dordrecht: Foris Publications, 1986.

OZZETTI, N. Entrevista [mensagem pessoal]. Mensagem recebida de <nozzetti@terra.com.br> em 01 maio 2005.

SCHOENBERG, A. Fundamentos da composição musical. São Paulo: Edusp, 1996. 